\title{
A formidable task: Population analysis predicts a deficit of 2000 cardiothoracic surgeons by 2030
}

\author{
Thomas E. Williams, Jr, MD, PhD, ${ }^{\text {a }}$ Benjamin Sun, MD, ${ }^{\mathrm{a}}$ Patrick Ross, Jr, MD, $\mathrm{PhD},{ }^{\mathrm{a}}$ and \\ Andrew M. Thomas, MD, MBA ${ }^{\mathrm{b}}$
}

\begin{abstract}
Objective: To estimate the cardiovascular workforce needed by 2030 to meet the needs of our population and to quantify its costs. Our field is changing. The volume of surgery and the nature of the surgery are changing. The nation's population grew from 227,000,000 to 282,000,000 between 1980 and 2000, and by 2030 the population is estimated to be $364,000,000$. At the same time, the applications for fellowship in our specialty are decreasing at an alarming rate. The American Board of Thoracic Surgery has certified 4500 cardiothoracic surgeons since 1975, but only 1300 in the last 10 years. The US Department of Health and Human Services predicts only 3620 full-time cardiothoracic surgeons in 2020. Will we have enough cardiovascular and thoracic surgeons?
\end{abstract}

Methods: Retrospective examination of the pertinent literature and with a modified Richard Cooper's economic trend analysis, a population algorithm with a ratio of physicians to population of 1.42 per 100,000. Each thoracic surgeon is predicted to practice 30 years from Board certification to retirement. The Balanced Budget Act will not be revised; therefore, we will certify 100 graduates from our programs per year. The assumed salaries will be $\$ 50,000$ with benefits of $30 \%$ and $\$ 15,000$ of additional Direct Medical Education costs.

Results: The population in 2030 will be $364,000,000$ with 5169 cardiothoracic surgeons needed at that time. Unfortunately, there will be approximately only 3200 cardiothoracic surgeons in practice with a shortage of approximately 2000. To maintain our current status per 100,000 population from 2011 to 2030, we will have to train 4000 residents. The total person years would be approximately 28,000 . The cost for this is more than $\$ 2,000,000,000$. The annual cost for this training prorated over 20 years would be more than $\$ 110,000,000$.

Conclusion: We must train approximately 4000 surgeons, an extra 100 per year, in our specialty to meet the needs of the population by 2030 . That will cost approximately $\$ 2,250,000,000$. To do this, the Balanced Budget Act of 1997 must be revised to permit more residents to be trained in the United States. (J Thorac Cardiovasc Surg 2010;139:835-40)

The nation's population grew from $227,000,000$ to $282,000,000$ between 1980 and 2000, and by 2030 the population will be $364,000,000 .{ }^{1}$ In our book, Consumer Driven Health Care, $^{2}$ we predicted there would be a shortage of 300,000 physicians by 2050 . How would that shortage affect the numbers of thoracic and cardiovascular surgeons?

The applications for fellowship in our specialty are decreasing at an alarming rate. The American Board of Thoracic Surgery has certified 4500 cardiothoracic (CT) surgeons since 1975 , but only 1300 in the last 10 years. The US Department of Health and Human Services predicts only 3620 full-time CT surgeons in 2020 . $^{3,4}$

\footnotetext{
From the Departments of Surgery ${ }^{\mathrm{a}}$ and Medicine, ${ }^{\mathrm{b}}$ The Ohio State University School of Medicine, Columbus, Ohio.

Disclosures: None.

This work was supported by a grant from the Columbus Medical Association Foundation.

Received for publication May 1, 2009; accepted for publication Dec 3, 2009; available ahead of print Feb 1, 2010.

Address for reprints: Thomas E. Williams, Jr, MD, PhD, Doan Hall, Room N-827, The Ohio State University Hospital, 410 West Tenth Ave, Columbus, OH 43210 (E-mail: tom.williams@osumc.edu).

$0022-5223 / \$ 36.00$

Copyright $(c) 2010$ by The American Association for Thoracic Surgery

doi:10.1016/j.jtcvs.2009.12.004
}

The Balanced Budget Act of 1997 "was enacted to control the growth of Medicare spending" and capped all medical and surgical residencies at 1996 levels without provision for population growth. Will this affect our problem? ${ }^{5}$

\section{MATERIALS AND METHODS \\ Workforce Analysis}

To predict our thoracic surgical workforce for 40 years, we established the number of thoracic and cardiovascular surgeons working in 2005 (personal communication, William Gay, MD, 2005). We then added the newly Board-certified surgeons entering the workforce and subtracted the number of thoracic surgeons leaving the workforce because of retirement, death, or disability. We combined those 3 projections to predict the total number of thoracic surgeons working every year. We used this method to predict the surgeons needed on a population basis in accordance with US Census Bureau estimates as we previously predicted for general surgery. ${ }^{6}$

\section{Assumptions}

There are 5 assumptions:

1. The 2005 ratio of surgeons per 100,000 population will be maintained, which was 1.42 thoracic surgeons per 100,000 population.

2. The number of thoracic surgeons in practice was approximately 4000 in 2005.

3. Each surgeon would practice 30 years from Board certification to retirement, death, or disability. 


\section{Abbreviations and Acronyms \\ $\mathrm{CT}=$ cardiothoracic}

4. There will be 100 Board certifications per year of graduating residents.

5. The postgraduate training positions would remain constant with no revision of the Balanced Budget Act of 1997.

\section{RESULTS}

\section{Calculation of Number of Surgeons Needed}

1. For an estimate of the thoracic surgeons needed per decade, the following formula is used: $[1.42 \times$ the estimated US population] divided by $100,000=$ the number of thoracic surgeons needed. The results are shown in Table 1. By 2010 we will have a shortage of approximately 553 thoracic surgeons. By 2030 that number is approximately 2000 , and by 2050 that number is approximately 3000 .

2. Calculation of surgeons leaving the workforce: Our algorithm assumes approximately 133 surgeons (ie, 4000 divided by 30 ) are leaving the workforce every year; that includes retirement, disability, and the death of the surgeons. As a result, by 2035, all of the surgeons will be retired, as illustrated in Figure 1.

3. The projection of new surgeons (we assume that there will be 100 new surgeons who will be certified by American Board of Thoracic Surgery each year): The number of newly Board-certified thoracic surgeons will increase to 3000 by 2035 , at which point it becomes stable as these people retire. The results are illustrated in Figure 1.

4. Calculation of the total number of thoracic surgeons in practice: From our initial number of 4000 practicing surgeons, we subtracted the number of older surgeons who had retired, been disabled, or died, and added the number of new surgeons recently Board certified; these projections are also illustrated in Figure 1.

By 2036, all of the practicing surgeons in 2005 have retired. Our boards will have certified 3000 new surgeons in that 30 years; the total of thoracic surgeons who are in active practice stabilizes at 3000 .

\section{Calculation of the Costs for Education}

1. We refer to the shortage for 2030 in Table 1, column 5 and enter it in Table 2, line 4. The shortage is 1994.

2. We will certify 2000 thoracic and cardiovascular surgeons in 20 years from 2011 to 2030, line 5 of Table 2.

3 . We add these 2 numbers and enter them in line 6 , total certification goal 2011 to 2030; this equals 3994 .
4. Divide the total certification goal 2011 to 2030 by 20 ; that equals the residents to be certified each year, 200, in line 7.

5. Multiply the residents to be certified each year by 7 and then by 20 to get 28,000 , the total resident years at 7 per resident in line 8 .

6. Multiply the 28,000 by $\$ 80,000$ to get the costs for Direct Medical Education at $\$ 80,000$ per year of resident training from 2011 to 2030, \$2,236,640,000, line 9.

7. Divide the Direct Medical Education costs at $\$ 80,000$ per year of resident training from 2011 to 2030 by 20 to get the annual costs of $\$ 111,832,000$ in line 10 .

Two hundred residents need to graduate per year to keep up with our increasing population (Table 2). This will cost our nation more than 2 billion dollars at an annual cost of more than 100 million dollars. This does not include the costs for Indirect Medical Education.

\section{DISCUSSION}

\section{Methodology}

There are 4 ways to perform projections of physician supply and the demand for physician services. The first is the work effort method advocated by Etzioni and colleagues. ${ }^{7}$ The second method is the inventory analysis of the US Government of US Department of Health and Human Services Health Resources. The third is Richard Cooper's method of economic trend analysis based on gross domestic product per capita. We use a fourth method, a simplified form of Richard Cooper's economic trend analysis, population analysis, which does not account for increases or decreases in gross domestic product per capita but gives agreement with Cooper's results within $5 \%$ of the total physician workforce. ${ }^{6-9}$

\section{Review of Assumptions}

Although it may not be possible to maintain the ratio of surgeons to population, that concept is essential to our method in doing the calculations. If the Balanced Budget Act is revised in this 20-year period, there will be more graduates certified. With the average age of graduates from our residencies between 31 and 36 years, it makes sense to forecast a period of 30 years from Board certification to retirement. A problem with our predictions is certifying 100 graduates each year; if we are not successful, our estimates are high for practicing surgeons (Figure 2).

\section{Analysis of Results}

Etzioni and colleagues ${ }^{7}$ conclude that the volume of thoracic surgery will be increased $18 \%$ by 2010 and $41 \%$ by 2020. Their method of workload analysis does not include the effects of changing technology to increase or decrease our workload; we cannot estimate that effect either. If we continue on this course, we will not have the numbers to meet that increased demand and we will have a deficit of approximately 2000 thoracic surgeons by 2030. Although 
TABLE 1. Thoracic surgeons needed and in practice

\begin{tabular}{cccccc}
\hline Year & $\begin{array}{c}\text { Projected } \\
\text { population }\end{array}$ & $\begin{array}{c}\text { Surgeons } \\
\text { needed }\end{array}$ & $\begin{array}{c}\text { Surgeons } \\
\text { in practice }\end{array}$ & Shortage & $\begin{array}{c}\text { Shortage } \\
(\%)\end{array}$ \\
\hline 2000 & $282,000,000$ & & & & \\
2010 & $309,000,000$ & 4388 & 3835 & 553 & $13 \%$ \\
2020 & $336,000,000$ & 4771 & 3505 & 1266 & $27 \%$ \\
2030 & $364,000,000$ & 5169 & 3175 & 1994 & $39 \%$ \\
2040 & $392,000,000$ & 5566 & 3000 & 2566 & $46 \%$ \\
2050 & $420,000,000$ & 5964 & 3000 & 2964 & $50 \%$ \\
\hline
\end{tabular}

2000 thoracic surgeons will be certified between 2011 and 2030, there will be a deficit of approximately 2000 .

The Physician Supply and Demand Projections of 2020 from the Health and Human Services Administration are 4100 active physicians in 2020 but only 3620 full-time equivalents. Our predictions agree with that within 5\% (Table 1 , column 4,3505$){ }^{8}$

Drivers of future demand for physicians are population growth and life expectancy, aging of the patient and population, public expectations, and lifestyle factors. The Association of American Medical Colleges predicts a shortage of approximately 160,000 doctors by $2025 .^{10}$ What will happen in a shortage? Practitioners will work longer hours, patients will have longer waits to get appointments and will travel greater distances to get their care, and hospitals and health care systems will face growing competition for surgeons. They will have to increase their recruiting, improve their retention policy, and pay particular attention to practitioner satisfaction.

In our estimate of educational expenses, we have used a figure of $\$ 80,000$ provided by Cooper in $2008 .{ }^{11}$ Our estimates include the resident salaries, their benefits, and other Direct Medical Education expenses. We do not include the Indirect Medical Education expenses and other costs associated with producing Board-certified surgeons. Therefore,

Thoracic surgeons

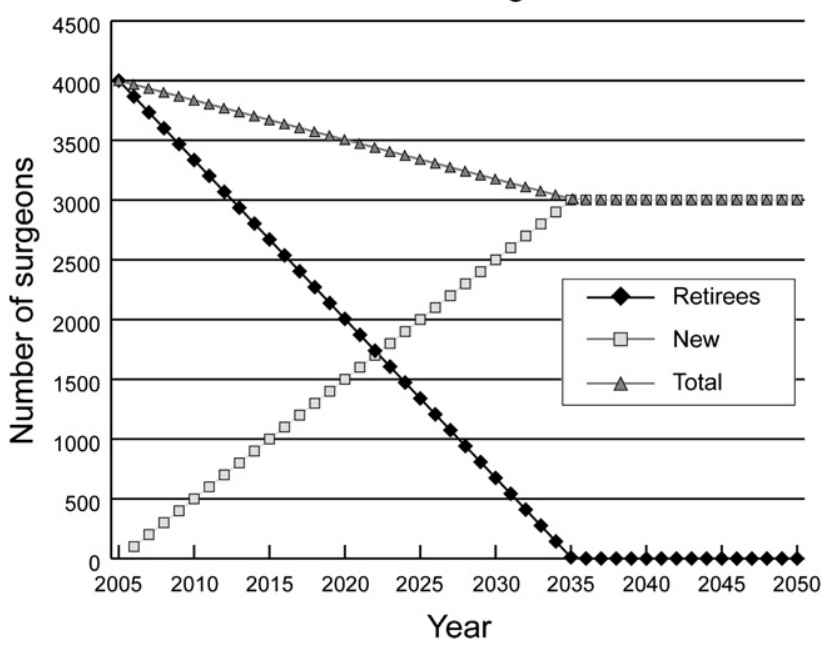

FIGURE 1. Total of thoracic surgeons.
TABLE 2. Calculation of costs

Population in $2030 \quad 364,000,000$

CT surgeons needed $\quad 5169$

CT surgeons in practice $\quad 3175$

Shortage 1994

Estimated to be certified, 2011-2030 2000

Total certification goal, 2011-2030 3994

Residents to be certified each year 200

Total resident years at 7 per resident 28,000

DME costs at $\$ 80,000$ per year of resident $\$ 2,236,640,000$ training for 2011-2030

Annual costs

$\$ 111,832,000$

$C T$, Cardiothoracic; $D M E$, Direct Medical Education.

our estimates for the educational expenses for residents, more than 2 billion dollars, are low.

\section{Workforce Estimates and Training Programs}

Cohn and colleagues ${ }^{12}$ noted increasing workloads for thoracic surgeons in their report in 1995; they also noted there were 289 CT residents serving from 1988 to 1989 . In 2002, the Society of Thoracic Surgeons predicted the shortage after noting that the National Residency Matching Program had reported that 21 of the 144 residents positions offered in that year were not filled. ${ }^{13}$

Shemin and colleagues, ${ }^{14}$ in their notable article, indicated that the thoracic surgery workforce was probably "right sized" until approximately 2010. Baumgartner, ${ }^{15}$ in his Presidential Address to the Society of Thoracic Surgeons in 2003, predicted a shortage in 10 to 12 years. Grover, ${ }^{16}$ in his Presidential Address in 2008, predicted an even more significant shortage (using only 75 Board certifications per year) in CT surgeons in the near future.

One strategy to increase the numbers of thoracic surgeons includes shorter training periods and part-time activity as

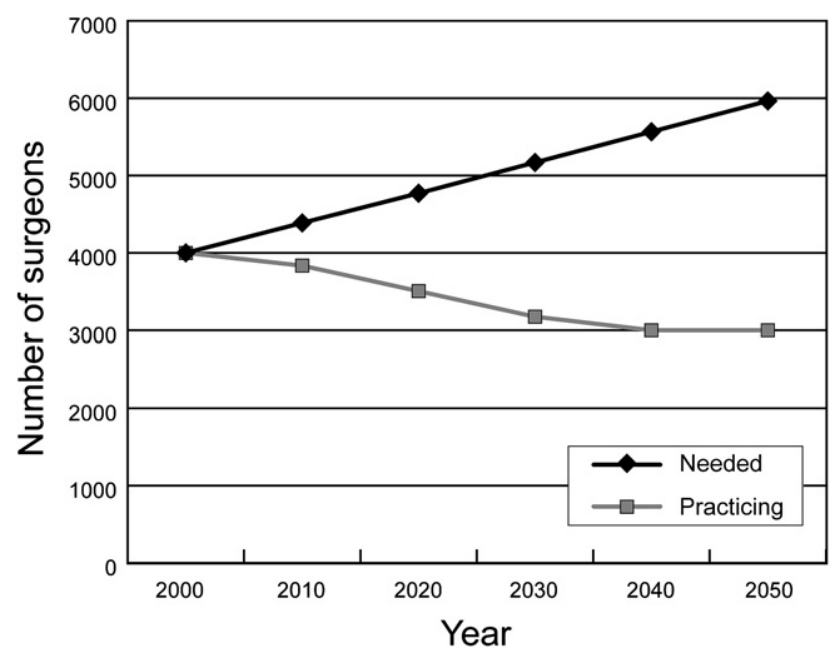

FIGURE 2. Thoracic surgeons needed versus supply (plot of columns 3 and 4 of Table 1 against year, column 1). 
people approach retirement. The shorter training might result in more applications to our residencies. The thoracic surgery matching program was first initiated in 1987. By 2005 there was a growing movement to reduce the years of cardiac surgical training. By adopting an integrated 6-year training program, the authors said we could shorten the training program by 1 year, as in the Canadian system. ${ }^{17}$

In our review of the 2008 match, there were 86 certified programs, of which 65 were filled. There were 118 certified first-year positions, and 94 of them were filled. There were 101 certified applicants for those positions, and 94 of them matched; 21 of them were international medical school graduates. In the 2007 match, only 87 positions were filled.

\section{Challenges: Personal and Financial}

One of the first challenges is to make a surgical career desirable for college students, particularly medical students, women, and minorities. One of the steps with regard to implementing this strategy is to have undergraduate students shadowing physicians in the hospital and their offices. We have to have medical students' clerkships on our services. Many medical schools do not require a CT rotation in their clinical years. When medical students go to the operating room with us, we have to let them have a more active role, and we also need to be more active in their education. We need to be mentors.

Should we adopt a version of the intersession program at Johns Hopkins where they have a 3-week rotation on the cardiac services at the Johns Hopkins Hospital for pre-med students? All 13 students in the first 3 years of the program applied to medical school. They also have a program for premedical and medical students to do CT research. In so doing, they mentor with the Johns Hopkins faculty. Finally, they offer a 2-week rotation for third-year medical students to rotate on their cardiac surgical service and even assign them to do donor runs when there are transplants scheduled. ${ }^{18}$

A positive experience may be the only way we can convince them of our passion for our patients and our field. There are profound intellectual and surgical challenges in what we do. We must show them there will be a market for their services when they go into CT surgery. There will be surgery for heart failure and surgery for cancer; more and more baby boomers will require surgical attention.

We must increase residents' salaries. A resident in CT surgery makes $\$ 50,000$ to $\$ 60,000$ per year. Someone with less than their education who is an associate serving at a prominent white shoe law firm in New York makes more than $\$ 160,000$ per year at age 26 years. ${ }^{19,20}$

One of our greatest challenges is to see if something can be done about the hours that medical students have to work after they go into practice. Dorsey and colleagues ${ }^{21}$ showed that a controllable or scheduled lifestyle is the leading factor for medical students' choices of specialties. We also have to address medical school students' debt. Stein- brook $^{22}$ said that the average debt is approximately $\$ 140,000$, with $23 \%$ of those medical students having debts of more than $\$ 200,000$. Merritt, Hawkins, Associates, ${ }^{23}$ in their 2008 survey of final year medical residents, indicated that one of their leading concerns is their medical school debt. The majority of final year residents would prefer a straight salary in their first year of practice.

An Association of American Medical Colleges survey indicates there are 250,000 physicians, approximately one third of the physicians working in 2005 , aged more than 55 years. ${ }^{24}$ If we could take advantage of the retirees as part-time surgeons, that would increase the numbers too. One of the barriers is the malpractice premiums that, in most states, do not include provisions of reducing the malpractice premiums for part-time employment. If, on the other hand, the retired surgeons could serve as hospitalists without any operating responsibilities, that could be a solution in some states. Certainly with 30 years in practice, we have the experience and knowledge to be part-time surgeons or hospitalists.

Reimbursements are a problem. Frederick Grover, in his Presidential address, noted the decline of reimbursements with regard both to the amounts and to the consumer price index. ${ }^{16}$ One consequence of this may be the end of private practice in CT surgery. We are seeing more and more employment of thoracic surgeons by hospitals. They are making a greater wage than they can make in private practice because of the reimbursements. The hospitals and regional health care organizations that employ them pay for their malpractice expenses, their office expenses, and other benefits, including both health insurance and retirement. As things evolve, more and more people will go to hospital employment because of hours and the other benefits. The hospitals' recruitment strategies include medical students' debt forgiveness, a signing bonus, and relocation expenses. ${ }^{23}$

\section{Challenges: The Congress of the United States}

Finally, our greatest challenge is with the Congress of the United States. They have to revise the Balanced Budget Act or we simply cannot train the residents. There is a great preference for primary care, but a patient cannot undergo an operation without the surgeon. We have to have the residency posts to educate our young surgeons. ${ }^{11}$

\section{CONCLUSIONS}

There will not be a sufficient number of trained CT surgeons to care for the American people as early as 2030 . That shortage will grow to 3000 by 2050 . If we can produce enough trainees to take care of our citizens by 2030 , the cost to the nation will be more than 2 billion dollars. To do that, the government must reform the Balanced Budget Act to increase the funding for medical and surgical trainees. Without this revision, and without the necessary surgeons, the population of this country will face rationing of procedures, access will be 
impaired, and we will be unable to give the high-quality medical and surgical care that we do in America today.

\section{References}

1. USA in 2050: Population Projected Over Five Decades. USA Today. March 18, 2004.

2. Blackwell RD, Williams TE, Ayers A. The crisis of the direct costs of health care. In: Consumer Driven Health Care. Ashland, OH: Book Publishing Associates; 2005:89-96.

3. Williams TE, Satiani B, Ellison EC. The Coming Shortage of Surgeons. Santa Barbara, CA: Praeger; 2009:28.

4. Physician Supply and Demand: Projections to 2020 US Department of Health and Human Services Health Resources and Services Administration Bureau of Health Professions October 2006. Health Resources and Services Administration, Department of Health \& Human Services. Physician Supply Projection, Tables 11 and 12. Available at: ftp://ftp.hrsa.gov/bhpr/workforce/PhysicianForecastingPaperfinal. pdf. Accessed April 13, 2009.

5. The Balanced Budget Act of 1997: a current look at its impact on patients and providers. Statement of Gail R. Wilensky, Chair Medicare Payment Advisory Commission. Before the Subcommittee on Health and Environment, Committee on Commerce, US House of Representatives, July 19, 2000. Available at: http:// pages.stern.nyu.edu/ jasker/BBA1.pdf. Accessed April 2, 2009.

6. Williams TE Jr, Ellison EC. Population analysis predicts a future critical shortage of general surgeons. Surgery. 2008;144:548-56.

7. Etzioni D, Liu J, Maggard M, Ko CY. The aging population and its impact on the surgery workforce. Ann Surg. 2003;238:170-6.

8. Physician Supply and Demand: Projections to 2020 US Department of Health and Human Services Health Resources and Services Administration Bureau of Health Professions October 2006. Health Resources and Services Administration, Department of Health \& Human Services. Available at: ftp://ftp.hrsa.gov/bhpr/ workforce/PhysicianForecastingPaperfinal.pdf. Accessed April 13, 2009

9. Cooper RA. Weighing the evidence for expanding physician supply. Ann Intern Med. 2004;141:705-14.

10. Association of American Medical Colleges. The State of the Physician Workforce: with Medical Expansion Underway, What's Next? Edward Salsberg. Presented November 2, 2008, San Antonio, Texas.

11. Cooper RA. It's time to address the problem of physician shortage: graduate medical education is the key. Ann Surg. 2007;246:527-34.

12. Cohn LH, Anderson RP, Loop FD, et al. Thoracic Surgery Workforce Report. The fourth report of the Thoracic Surgery Committee of The American Association for Thoracic Surgery. J Thorac Cardiovasc Surg. 1995;110:570-85.

13. The Society of Thoracic Surgeons. Shortage of New Heart Surgeons Predicted. Press Release. August 6, 2002.

14. Shemin RJ, Dziuban SW, Kaiser LR, et al. Thoracic surgery workforce: snapshot at the end of the twentieth century and implications for the new millennium. Ann Thorac Surg. 2002;73:2014-32.

15. Baumgartner WA. Cardiothoracic surgery: a specialty in transition-good to great? Ann Thorac Surg. 2003;75:1685-92.

16. Grover FL. The bright future of cardiothoracic surgery in the era of changing health care delivery: an update. Ann Thorac Surg. 2008;85:8-24.

17. Dunnington G, Pelletier MP. The future of cardiac surgery training programs. Ann Thorac Surg. 2006;81:1179-80.

18. Gott VL, Patel ND, Yang SC, Baumgartner WA. Attracting outstanding students (premedical and medical) to a career in cardiothoracic surgery. Ann Thorac Surg. 2006;82:1-3.

19. Johnson JA. Clinical instructor housestaff stipend level fiscal year 2008, July 2007- June 2008. The Ohio State University, Department of Surgery.

20. The New York Job Source. Sullivan and Cromwell. Available at: http:// nyjobsource.com/sullivancromwell.html. Accessed April 2, 2009.

21. Dorsey ER, Jarjoura D, Rutecki GW. Influence of controllable lifestyle on recent trends in specialty choice by US medical students. JAMA. 2003;290:1173-8.

22. Steinbrook R. Medical student debt-is there a limit. N Engl J Med. 2008;359: 2629-32.

23. Merritt, Hawkins, and Associates. 2008 Survey of Final Year Medical Residents. Available at: http://www.merritthawkins.com/pdf/2008-mha-survey-medicalresidents.pdf. Accessed April 13, 2009.

24. Association of American Medical Colleges. Help Wanted: More U.S. Doctors. Projections Indicate America Will Face Shortage of M.D. by 2020. Available at: http://aamc.org/workforce/helpwanted. Accessed April 13, 2009.

\section{Discussion}

Dr Irving Kron (Charlottesville, $\mathrm{Va}$ ). The authors make the case that there will be a predicted shortage of surgeons in the United States by the year 2030. The American Association for Thoracic Surgeons and the Society of Thoracic Surgeons in association with the Association of American Medical Colleges developed an article that is now in press in Circulation that pretty much comes up with the same conclusion, about a $25 \%$ shortage of CT surgeons by 2025 .

The authors come up with multiple potential solutions, including shortening training, increasing salaries, and increasing interest in medical students in our specialty. These are all wonderful ideas, but I am not sure that is the entire answer.

The first question to the authors is, will there really be a shortage? That is something we had difficulty with in our article, of course What we can't predict is whether there will be different kinds of procedures, such as percutaneous aortic valves, that may markedly affect what our specialty does. How do these models take those things into account? In addition, what if we change the way we deliver care? If we regionalize, I don't think we would need 1 or 2 surgeons in every small program.

My final comment relates to the issue of why we don't attract people to our specialty, and it is a real issue. In fact, the job market is probably getting a little bit better, but the number of applicants have not changed and may actually be reduced this year. As you know, the Joint Council on Thoracic Surgical Education is looking at this particular issue. What we are struggling with is not how you attract residents, there are ways to attract people, but can you maintain the quality? I would like the authors' thoughts on that.

Dr Sun. Is there really a shortage? I think everybody in this room would love to have a formula to try to figure that out. When we do these population-based studies, the wild card is technology, and that is, unfortunately, something that is unpredictable. Yet at the same time, we are hopeful that our Society and our field move along with technology and are participants of technology and evolution of our practice.

I would like to say that we went through eras when we were the leaders and innovators in the field. For a while we became producers and provided an excellent service, which is therapy for a lot of our patients. With pressure back on our field, we are back in the innovation mode, which I think is healthy for us.

Trying to answer that question is extraordinarily difficult, because technology can put all of us out of business if we develop some therapy that dissolves plaque disease and has a way to shrink all malignancies with a noninvasive therapy. We will have a different challenge. But seeing that those things are not likely to occur in our lifetimes, we have to plan for a potential real problem that exists, which is the growth of our population and the increase in diabetes, obesity, and other risk factors associated with the diseases that we manage, and will likely contribute, to some extent, to the growth of therapies needing our help and our skills. This is a moving target, and one of the flaws of our presentation is that we have a fixed ratio, and that ratio may vary by year. We are assuming a CT surgeon ratio of 1.42 physicians per 100,000 population. That ratio may eventually be 1.2 or maybe 1 per 100,000 . It probably is not going to be 0.5 or 0.8 . So we still think that this is going to be a shortage for us.

Your second question specifically addresses our residency and bringing people into our field. Because all of us are part of training 
programs, or many of us are part of programs, one of the areas that has been the biggest struggle for us is exposure, and I think Dr Williams mentioned that as well. When people see what we do, when people "play" with us, that is where we get them interested. We have to take ownership of this as well and be good role models and teachers to provide a good experience, and give them the idea that this is a field worth going into. I think we still have a perception problem, which is that there are not that many jobs out there, and these are the kinds of information that we need to get out for ourselves and say, let's do a survey, let's see how many open positions there are, to try to dispel some of those kinds of impediments to people going into our field. 